\title{
Conceptual Frame work of Adolescent health Trend in India.
}

\author{
${ }^{1}$ Ashoka S R, ${ }^{2}$ Dr. N K Gayatri \\ ${ }^{I}$ Research Scholar D.O.S. in Economics \& Co-operation Manasagangotri, University of \\ Mysore, Mysore District, \\ ${ }^{2}$ Associate Professor, D.O.S. in Economics \& Co-operation, Manasagangotri ,University of \\ Mysore, Mysore District.
}

\begin{abstract}
This paper mainly concentrate towards the trends which have been already grown in the name of fashion or Modernization in young generation in our country. Why this particular age group has been chosen means adolescent age group includes 10-19 years and this age groups lies in the younger generation which more constitutes in India that's why India is regarded as young nation. Now a days in the name of fashion or modernization youngsters mentioned in the above age group are neglecting their health. The negligence of Government is purely responsible for this kind of attitude which we can see in this age group, because as we know the government allowing these kind of harmful commodities into the market without providing substitutes for those who are engaged in producing harmful commodities. It is not only harmful for those who consume it, but also it is for the producers. Bearing this in mind this paper discusses about the attitude of young generation, negligence of government, failure in implementation of strict measures in the context of having healthy nation. And also make discussion about the healthy human resources because as it is called the Indian economy labour intensive economy by comparing to the other developed countries. The most of young generation eager with their activities like illigulal sexual activities, bike stunts or other harmful activities, its results accidents many cases soling their valuable life. We are knowing that now a day's young generation they have more sensitivity in their thinking become attempting suicides. It implies the adverse effect pertaining to have a good health. By comparing china it has most populated country in the world although it has implemented strict measures in the view of achieving socio-economic development but India has moving towards the achievement of economic development but it has failure in progress of social developmental activities.
\end{abstract}

\section{Introduction:}

The term adolescence is derived from the Latin word "adolescere" meaning to grow, to mature. Adolescence is a journey from the world of the child to the world of the adult. It is a time of physical and emotional change as the body matures and the mind becomes more questioning and independent. This period is most crucial since these are the formative years of life of an individual when major physical, psychological \& behavioral changes takes palce. This is also the period of preparation for undertaking greater responsibilities including healthy responsible parenthood. Future of the society depends on adolescents and they form a great human resource for the society.

Adolescents (10-19 years) constitute about one fourth of India's population and young people (10-24 years) about one third of the population. This huge section of population represents a great 'demographic dividend' and offers a dependable potential to drive and sustain economic growth that India has experienced in last few years.

In order to fulfill this potential the nation must be able to invest in their education, health and development adequately. In order to ensure that they grow healthy they require information and skills, health services and counseling as well as a safe and supportive environment. Adolescents are generally considered healthy by themselves, their families, even health care providers and society at large. Yet they are known to suffer significant morbidity caused by risk taking behavior and inadequate access to health care. In addition, programmes and services must recognize their special needs and address these in a supporting and nonjudgmental manner. This requires a better understanding of their existing status within the prevailing sociocultural settings and their vulnerabilities.

Adolescents have always remained in a dilemma, as they are neither considered children nor adults. A similar fate seems to follow the development of a comprehensive policy on Adoles-cent Reproductive and Sexual Health (ARSH) in India mainly due to lack of inter-ministerial collaboration, socio-cultural and politicoreligious factors. India has about 230 million adolescents in the age group $10-19$ years, with females comprising about $47 \%$ of the total adolescent population (GOI, 2001). It is this adolescent population which will enter the workforce in the next 5 - 15 years, and play a vital role in India's socio-economic development. Internationally, ARSH1 has become a priority programme approach to help the future generations have a safe, healthy and satisfactory life. 
Conceptual Frame work of Adolescent health Trend in India.

\begin{tabular}{|ll|l|}
\hline$\bullet$ & Adolescence & $10-19$ years \\
\hline$\bullet$ & Early Adolescence & $10-13$ years \\
\hline$\bullet$ & Middle adolescence & $14-16$ years \\
\hline$\bullet$ & Late adolescence & $17-19$ years \\
\hline$\bullet$ & Youth & $15-24$ years \\
\hline$\bullet$ & Young people & $10-24$ years \\
\hline
\end{tabular}

Early adolescence (10-13): is characterized by a spurt of growth, and the beginnings of sexual maturation. Young people start to think abstractly

In mid-adolescence (14-15): the main physical changes are completed, while the individual develops a stronger sense of identity, and relates more strongly to his or her peer group, although families usually remain important. Thinking becomes more reflective.

In later adolescence (16-19): the body fills out and takes its adult form, while the individual now has a distinct identity and more settled ideas and opinions.

\section{Objectives of this study}

$>$ To study the Importance of adolescence health

$>$ To study the adolescence health programmes

$>$ To study the problem of adolescence health

\section{Methodology}

On the basis of the above mentioned objectives, the following methodology will be adopted in this article. This has been analyzed under various sub headings as follows.

\section{Data Sources:}

This study is purely based on the secondary data. The secondary data is collected from the published articles, books, documents, theses, periodicals, newspapers, internet sources. This secondary data is related to the developing countries of the India has been selected for the study area. It is relating to the implementation of the adolescents health.

\section{Importance to of pay attention the health of adolescents}

$>$ To reduce death and disease in adolescents: An estimated 1.7 million young people aged from 10 to 19 die each year - mainly from accidents, violence, pregnancy related problems or illnesses that are either preventable or treatable. Many more develop chronic illness that damages their life.

$>$ To reduce the burden of disease in later life: Malnutrition in childhood and in adolescence can cause lifelong health problems, while failure to care for the health needs of young pregnant women can damage their own health and that of their babies. This is the age when sexual habits and decisions about risk and protection are formed. Some of the highest infection rates for sexually transmitted infections are in adolescents. The HIV/AIDS pandemic alone is sufficient reason to look a new at how health services address the needs of adolescents. Many diseases of late middle age, such as lung cancer, bronchitis and heart disease, are strongly associated with a smoking habit that begins in adolescence.

$>$ To invest in health Healthy and unhealthy practices adopted today may last a lifetime. Today's adolescents are tomorrow's parents, teachers and community leaders. What they learn they will teach to their own children. Adolescence is a period of curiosity, when young people are receptive to information about themselves and their bodies, and when they begin to take an active part in decision making.

$>$ To protect human capital: In some societies two out of three adolescents are involved in productive work, while many young women below the age of 20 are already mothers. If they are no longer able to fulfill these roles because of injury, illness or psychological damage, the cost is primarily a human one, but there is also a cost to society.

\section{Adolescent Health Programs:}

1. Kishori Shakti Yojana : To improve the health and nutritional status of girls

2. Balika Samridhi Yojana: To Delay the age of marriage

3. National AIDS Control Programme

4. Reproductive and Child Health Programme

1. Kishori Shakti Yojana: This scheme is a redesign of the already existing Adolescent Girls (AG) Scheme being implemented as a component under the centrally sponsored Integrated Child Development Services (ICDS) Scheme.

Kishori Shakti Yojna (KSY) - a key component of ICDS scheme which aims at empowerment of adolescent girls. Kishori Shakti Yojana (KSY) seeks to empower adolescent girls, so as to enable them to take 
charge of their lives. The programme through its interventions aims at bringing about a difference in the lives of the adolescent girls. It seeks to provide them with an opportunity to realize their full potential. Under the Scheme, the adolescent girls who are unmarried and belong to families below the poverty line and school dropouts are selected and attached to the local Anganwadi Centres for six-monthly stints of learning and training activities. This includes two sub-schemes,

Scheme- I (Girl to Girl Approach) : The Scheme-I has been designed for adolescent girls in the age group of 11-15 years belonging to families whose income level is below Rs. 6400/- per annum

Scheme-II (Balika Mandal): The Scheme-II is intended to reach to all adolescent girls in the age group of 1118 years irrespective of income levels of the family. It may however, be mentioned that even under Scheme-II, younger girls in the age group of 11-15 years and belonging to poor families are also included.

\section{Objective of this Programme}

- To improve the nutritional and health status of girls in the age group of 11-18 years;

- To provide the required literacy and numeracy skills through the non-formal stream of education, to stimulate a desire for more social exposure and knowledge and to help them improve their decision making capabilities

- To train and equip the adolescent girls to improve/ upgrade home-based and vocational skills

- To promote awareness of health, hygiene, nutrition and family welfare, home management and child care, and to take all measure as to facilitate their marrying only after attaining the age of 18 years and if possible, even later

- To gain a better understanding of their environment related social issues and the impact on their lives

- To encourage adolescent girls to initiate various activities to be productive and useful members of the society

Other options of the programme:

- IFA supplementation along with deforming

- Education for school dropouts and functional literacy among illiterate adolescent girls

- Non-formal education to adolescent girls. Emphasis on life education aspects including physical, developmental and sex education is given.

- Vocational training activities may be undertaken for adolescent girls for their economic empowerment. At Anganwadi Centres, a group of 20-25 girls may be identified by the Supervisor (Mukhya Sevika). Of these, nomination of 2 selected girls from each Anganwadi Centre may be sent to the Office of District Programme Officer. District Programme Officer in consultation with CDPO, officer's in-charge of these sectors and NGOs will organize vocational training courses, non-formal education course, life education courses, health and nutrition education, legal literacy etc. Following completion of the training, the group leaders ( 2 adolescent girls from each Anganwadi Centre) will provide training to the remaining adolescent girls at Anganwadi Centre.

2. Balika Samridhi Yojana: The scheme of Balika Samridhi Yojana was launched by Govt. of India in1997 with the following objectives:-

1. To change negative family and community attitudes towards the girl child at birth and towards her mother.

2. To improve enrollment and retention of girl children in schools

3. To increase the age of marriage of girls.

4. To assist the girl to undertake income generation activities.

Components of Balika Samridhi Yojana: From the start of the scheme, the mothers of newborn girl children were given a post delivery grant of Rs. 500/- each in cash as a gift from the Government. There was also provision for Annual Scholarships to the girl child for attending school. (But the details /guidelines for scholarships were not received).

During 1999-2000, Govt. of India recast the scheme and the benefits and means of delivery have been redesigned to ensure that financial benefits accrue to the girl child. Now the girl children eligible under BSY are entitled to the following benefits:-

1. A post birth grant amount of Rs. 500/-

2. When the girl child born on or after 15-08-1997 and covered under BSY starts attending the school, she will become entitled to annual scholarship as under for each successfully completed year of schooling:- 
Conceptual Frame work of Adolescent health Trend in India.

\begin{tabular}{|l|l|}
\hline Class & Amount of Annual Scholarship \\
\hline I-III & Rs. 300/- per annum for each class \\
\hline IV & Rs. 500/- per annum \\
\hline V & Rs. 600/- per annum \\
\hline VI-VII & Rs. 700/- per annum for each class \\
\hline VIII & Rs. 800/- per annum \\
\hline IX-X & Rs. 1000/- per annum for each class \\
\hline
\end{tabular}

Coverage: Balika Samridhi Yojna is being implemented in both rural and urban areas.

Target group: Under Balika Samridhi Yojana girl children belonging to families below the poverty line are given benefit, who are born on or after 15th August, 1997. The benefits are restricted to two girl children in a household irrespective of number of children in the household.

Procedure for obtaining the benefit: This scheme is being implemented through ICDS infrastructure in rural areas and through functionaries of Health Department in urban areas. The application forms are available with Anganwadi Workers in the villages and with Health functionaries in urban areas. The beneficiaries are required to submit the filled in applications to these functionaries.

Facility of withdrawal: A portion of the Post Birth Grant of Rs.500/- or the amount of the annual scholarship can be applied toward the sole purpose of paying the premium on an insurance policy in the name of the girl child under the Bhagyashri Balika Kalyan Bima Yojna. The amounts of annual scholarships can also be permitted to be utilised toward purchase of textbook or uniform for the girl child. The amount left after payment shall be deposited in the account

Payment at maturity: On the girl child attaining 18 years of age and on production of a certificate from the Gram Panchayat /Municipality that she is unmarried on her eighteenth birthday, the implementing agency would authorise the bank or the post office authorities concerned to allow her to withdraw the amount standing in her name in the interest bearing account.

Withdrawal of the benefit: In the event of the girl getting married before attaining the age of 18 years, she shall go for the benefit of the amount of annual scholarships and the interest accrued there on and shall stand entitled only to the Post Birth Grant amount of Rs.500/- and the interest accrued there on. In the eventuality of the death of the girl child before attaining the age of 18 years, the accumulated amount in her account would be withdrawn.

Funds: Prior to 1999-2000, funds were being released to the Additional Deputy Commissioners by the Government of India. However, there after the funds were being released to the State Govt.

3. National AIDS Control Programme: Reaching youngsters at an impressionable age before they become sexually active can lay the foundation for a responsible lifestyle, including healthy relationships and safe sex habits. Under NACO Adolescent Education Programme developed which focuses primarily on prevention through awareness building The Adolescent Education Programme is one of the key policy initiatives of NACP II. NACO collaborated to develop this school-based programme which is implemented across 144,409 secondary and senior secondary schools with the objective of reaching out to about 33 million students within two years. AEP is implemented by the Department of Education in collaboration with the State AIDS Prevention and Control Societies.

The Adolescence Education Programme (AEP):

- Co-curricular adolescence education in classes IX-XI

- Curricular adolescence education in classes IX-XI and life skills education in classes I- VIII

- Inclusion of HIV prevention education in pre-service and in-service teacher training and teacher education programmes.

- Inclusion of HIV prevention education in the programmes for out-of-school adolescents and young persons, and

- Incorporating measures to prevent stigma and discrimination against learners/students and educators and life skills education into education policy for HIV prevention.

Under the programme, teachers and peer educators are trained who in turn conduct the programme amongst the student community. The programme covered 112,000 schools and trained 2,88,000 teachers. They have been provided reference material, which has been developed by NACO. Relevant messages on safe sex, sexuality and relationships are developed and disseminated for youth via posters, booklets, panels and printed material.

YUVA - Youth Unite for Victory on AIDS: A youth network, Yuva comprising seven youth organisations, Nehru Yuva Kendra Sangathan, National Service Scheme, Indian Red Cross Society, National Cadet Corps, Bharat Scouts and Guides, Youth Hostels Association of India and the Association of Indian Universities, working for the young people with prevention, education and life skills for promoting healthy and safe 
behaviour and practices amongst them. The ultimate goal is to have an "AIDS prepared Campus, AIDS prepared Community and AIDS prepared Country".

Red Ribbon Club (RRC): Red Ribbon Club is a voluntary on-campus intervention programme for students in educational institutions. It is initiated and supported by the SACS and implemented through multisectoral collaboration, particularly using the services of cadre officers of the State's NSS. The club is proposed to be established in every school and college to provide youth with access to information on HIV/AIDS and voluntary blood donation. The club also works towards promotion of life skills to bring about behavioural change among the youth. Already RRCs are established in more than 16,000 schools and colleges.

4. Reproductive and Child Health Programme: The adolescent health initiative in RCH II

Reproductive and Sexual Health (ARSH): Services provided to all adolescent married and unmarried girls and boys

\section{Package of services}

1. Promotive services:

- Focused care during antenatal period

- Counseling \& provision of emergency contraceptives

- Counseling \& provision of reversible contraceptives

- Information/advice on SRH services

2. Preventive services:

- Services for TT and prophylaxis against nutritional anemia

- Nutritional counseling

- Services for early and safe termination of pregnancy and management of post abortion complications

3. Curative services:

- Treatment for common RTI/STIs

- Treatment \& counseling of menstrual disorders sexual concerns of males and female adolescents

- Management of sexual among girls

4. Referral services:

- Voluntary Counseling and Testing Centre

- Prevention of Parent to Child Transmission

5. Outreach services:

- Periodic health checkups and community camps

- Periodic health education activities

- Co-curricular activities

5. Adolescent Friendly Health Services: AFHS provides a broad range of preventive, promotive \& curative services under one roof \& which helps to ensure improved availability, accessibility \& utilization of health services. It is being initiated by government, private \& NGO's. The significant feature of AFHS is provision of reproductive health services, nutritional counseling, sex education \& life skill education. It is kind of one-stop shopping approach which means that different needs of adolescent can be met under one roof by professional who understand their needs $\&$ are trained to address them effectively.

AFHS in India is first taken by Safdarjang Hospital in New Delhi that is providing a wide range of services such as clinical, mental health services, nutritional \& reproductive counseling, growth monitoring \& development \& immunization The National Institute of Research in Reproductive Health, Mumbai in collaboration with Municipal cooperation of Mumbai started AHFS under the name "Jagruti" for providing specialized sexual \& reproductive services for adolescent boys \& girls MAMTA an NGO started AFHS in some villages. This model comprises community based Youth Information Centers (YIC's) supported by peer educators, health facility based youth clinics at primary health centers \& youth friendly centers at first referral unit. In four districts of Madhya Pradesh a pilot project of AFHS launched as name "Jigyasa" by The Family Planning Association of India(FPAI) The RCH-II has a strategy to provide services for adolescent health at public health facilities \& at primary health care level during routine hours and on dedicated days \& times. Public health personnel such as medical officers as well as ANM's \& lady health visitors will receive training on the provision of sexual \& reproductive health services exclusively for adolescents. Haryana is the first state in the country to launch a distinct Adolescent Reproductive \& Sexual Health (ARSH) program providing AFHS at government health facilities. 
Health problems of adolescents:

> General health problems: Adolescents are subject to most of the same illnesses as other age groups within the population. However, they are much less likely to recognize symptoms, and much more likely to underestimate their importance. In addition, they usually do not know where to go for help. As a result adolescents are the least likely section of the population to go for early treatment. They may leave diseases untreated because they are afraid of the outcome, worried about the stigma or do not believe that they will be treated well at a clinic.

> Malnutrition: When there is a shortage of food, most families know that they must make special efforts to ensure that babies are well nourished. It is less well understood that adolescent girls and boys have a need for extra nutrition as they grow rapidly and develop and that an inadequate diet can delay or impair healthy development. Stunting can occur in childhood or during adolescence. In some cultures girls are fed last and fed least. In girls, poor nutrition can delay puberty and lead to the development of a small pelvis. Malnourished adolescent girls who have babies at a young age are more likely to experience, and will be less able to withstand, complications because the body has not yet reached maturity. Maternal mortality is higher in anemic women. Even when they survive, poorly nourished adolescent mothers are more likely to give birth to low birth-weight babies, perpetuating a cycle of health problems which pass from one generation to the next.

$>$ Anemia is also one of the most important problem among adolescents

$>$ In a growing number of developing countries, obesity and eating disorders exist along side malnutrition. In extreme cases eating disorders such as bulimia and anorexia can permanently damage physical and mental health. Obesity itself is a major problem in some societies. A failure to deal with this at a young age, can lead to a lifetime poor health and unhappiness and an early death.

> Mental health problems: Mental health problems may first become apparent during adolescence. A young person experiencing depression or another mental health problem has no frame of reference for his or her condition and may not recognize this as an illness or seek treatment. Mental health problems frequently start to make themselves felt in this age group. Depression is common, especially for young people who have low self-esteem. They may feel that they have no future or are useless. Depression reduces the quality of a young person's life at a time when he or she should be full of optimism and hope. A young person who sees no future is more likely to take risks with his or her health. Depression can also lead to the ultimate tragedy — almost 90,000 young people commit suicide each year across the world.

> Early \& unprotected sex: Many young people become sexually active without planning the sexual relationship or thinking about the consequences. This results into the high number of unwanted pregnancies and unsafe abortions and the steep rise in HIV infection. Adolescents live in increasingly sexualized societies, exposed to mass media that challenge cultural values. The rapid growth of cities and the breakdown of traditional family structures erode a protective cultural layer. Conflict and forced migration put many young people at risk.

Strategies for promotion of adolescent health:

A =Adoption of healthy life style

$\mathrm{D}=$ Develop appropriate i.e. strategy discourage early marriage and teenage pregnancy

$\mathrm{O}=$ Organize adolescent/ youth friendly clinic

$\mathrm{L}=$ Life skill training, legal support, liaison with peers, parents

E=Educate about sexuality, safe sex, spirituality, responsible parenthood

$\mathrm{S}=\mathrm{Safe}$, secure and supportive environment to be provided

$\mathrm{C}=$ Counseling / curriculums in school inclusive of family life education

$\mathrm{E}=$ Enable \& empower for responsible citizenship

$\mathrm{N}=$ Networking for experience sharing

$\mathrm{T}=$ Training for income generation, teen clubs

\section{Conclusion}

The most of young generation eager with their activities like illegal sexual activities, bike stunts or other harmful activities, its results accidents many cases losing their valuable life. We know that now a day's young generation they have more sensitivity in their thinking, become attempting suicides. It implies the adverse effect pertaining to have a good health. By comparing china it has most populated country in the world although it has implemented strict measures in the view of achieving socio-economic development but India has moving towards the achievement of economic development but it has failure in progress of social developmental activities but above the implementation of programmes helpful to increasing the adolescent health. It has very 
effective to improve the Human development. Although not enough to health facilities compare to other forward countries.

\section{Reference:}

[1]. Chopra H. Overview of adolescent health in India. Indmedica.

[2]. Nair MKC. Adolescent sexual and reproductive health. Indian Pediatr. 2004;41(1):7-13.

[3]. United Nations. The Millennium Development Goals Report 2011. New York: United Nations;June 2011.

[4]. World Health Organization. Helping parents in developing countries improve adolescents' health. Geneva:WHO; 2007.

[5]. Gupta SD. Adolescent reproductive health in India: status, policies, programs, and issues. Washington, DC: Futures Group International,POLICY,USAID;2003.

[6]. McIntyre P. Adolescent friendly health services: an agenda for change. Geneva: World Health Organization; 2002.

[7]. Government of India. Implementation guide on RCH-II adolescent reproductive sexual health strategy. New Delhi: Ministry of Health \& Family Welfare; 2006

[8]. Safdarjung Hospital Adolescent Healthcare Network. Establishing adolescent friendly health services at Safdarjung hospital, New Delhi, end of term report 2005. New Delhi:Safdarjang Hospital; 2005.

[9]. Indian economic servey.

www.indian health misson

www.adolescent health

www.Importance of the adolescent health

www.Programmes of the adolescent health

www.Problem of the adolescent health 